\title{
GUIA DE APLICAÇÃO DE TOXINA BOTULÍNICA PARA O TRATAMENTO DE CEFALEIA TENSIONAL
}

\section{Amanda M. Okamoto*, Paulo Henrique F. Caria.}

\section{Resumo}

As dores de cabeça podem ser classificadas clinicamente em primárias e secundárias. As primárias ocorrem sem doenças orgânicas subjacentes e podem ser ainda classificadas em enxaquecas, dores de cabeça e dores de origem tensional. Essa última tem apresentado excelentes resultados quando tratada com toxina botulínica do tipo $A$ (TXB-A). Para que se tenha sucesso no tratamento da cefaleia tensional com TXB-A, é fundamental que se conheçam detalhes anatômicos do músculo temporal.

\section{Palavras-chave:}

toxina botulínica, músculo temporal, cefaleia tensional.

\section{Introdução}

As cefaleias podem ser clinicamente classificadas em primárias e secundárias, ou simplesmente em enxaquecas, dores de cabeça e dores de origem tensional. As diferentes causas das cefaleias são distúrbios nervosos e musculares, por isso a toxina botulínica do tipo A (TXB-A) vem sendo amplamente empregada no tratamento das dores de origem tensional. A TXB-A proporciona menos efeitos colaterais e apresenta maior duração do efeito quando comparada a alguns medicamentos comumente usados. A TXB-A é aplicada em diferentes músculos para o tratamento da cefaleia tensional, dentre eles o músculo temporal.

Para realizar estas injeções, é essencial que se conheça os detalhes anatômicos da região. O objetivo deste projeto é fornecer diretrizes anatômicas para distinguir o músculo temporal, seu tendão e vasos adjacentes, atingindo o alvo, produzindo maior eficácia clínica usando a menor concentração possível de TXB-A.

Este estudo comparou dois métodos diferentes, medidas lineares (método 1) e identificação através de uma estrutura de quadrantes (método 2). Vinte músculos temporais (hemifaces) foram usados. Os músculos foram dissecados para descrição de sua forma e tamanho e a veia temporal média, a artéria temporal superficial, o ventre muscular e seu tendão foram identificados.

\section{Resultados e Discussão}

Método I - Localização e forma do tendão temporal: acima do arco zigomático e forma retangular e oblíqua. Classificação: tipo I $(4,6 \%)$, tipo II $(88,6 \%)$ e tipo III $(6,8 \%)$.

As medições das linhas verticais e horizontais apresentaram: L0: 8,85mm $\pm 3,91$; L1: 21,69mm $\pm 1,84$; L2: $43,39 \mathrm{~mm} \pm 3,68 ;$ L3: $60,47 \mathrm{~mm} \pm 4,85$ e L4: $77,54 \mathrm{~mm}$ $\pm 6,92$.

Método II - A largura média da TM (A0 - P0): 117,6mm.

Altura média ( $\mathrm{AO}$ - S0): 96mm.

A relação média entre largura e altura: 5:4

Embora os valores numéricos de largura e altura variem entre os espécimes, a relação largura-altura apresentou proporções quase idênticas.

A distância média entre $\mathrm{AO}$ e $\mathrm{C}$ foi de $3 \mathrm{~mm}$. Distância média entre P0 e T: 26,5mm. Distância média de T a E0 $29 \mathrm{~mm}$ (variação de 27 a $31 \mathrm{~mm}$ ). A distância entre T e P0 e a distância média entre $T$ e EO foram igualmente de $2,5 \mathrm{~mm}$.
A aplicação da TXB-A no músculo temporal auxilia no alívio da cefaleia tensional, contudo seu mecanismo não está claro. Este estudo permitiu identificar locais e distâncias seguras para a aplicação de TXB-A em uma amostra de indivíduos brasileira.

Existem muitas estruturas anatômicas críticas, como artérias, veias e o nervo facial na região temporal, por isso injeções nesta área envolvem risco de danos aos vasos sanguíneos e ao indivíduo. A redução desses é útil para evitar a ocorrência de efeitos adversos pós-injeção
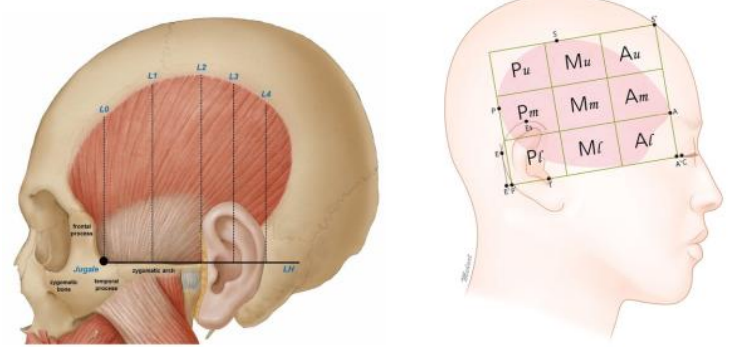

Figura 1. Desenho esquemático dos pontos de referência e linhas baseadas em estruturas anatômicas de superfície; (Método 1)

Figura 2. Linhas de referência e pontos anatômicos para medições na região temporal. (Método 2 )

\section{Conclusões}

Ambas as análises ofereceram referências importantes para realizar uma injeção bem-sucedida de TXB-A no músculo temporal, ao menos $40 \mathrm{~mm}$ verticalmente acima do arco zigomático e nos quadrantes $\mathrm{Mu}$ e $\mathrm{Mm}$, para evitar grandes vasos sanguíneos e tendões, promovendo segurança e eficácia clínica com reduzidos contratempos.

\section{Agradecimentos}

Agradeço ao meu orientador, por todo o suporte durante a elaboração deste projeto, e ao CNPq pela bolsa de iniciação científica concedida.

1. Carruthers, J.; Carruthers, A. Botulinum toxin (Botox) chemodenervation for facial rejuvenation. Facial Plast Surg. Clin. North Am. 2001, 9, 197-204.

2. Göbel, H.; Heinze, A.; Heinze-Kuhn, K.; Jost, W.H. Evidence-based medicine: Botulinum toxin A in migraine and tension type headache. J. Neurol. 2001, 248, 34-38.

3. Heckmann, M.; Ceballos-Baumann, A.O.; Plewig, G. Botulinum toxin A for axillary hyperhidrosis (excessive sweating). N. Engl. J. Med. 2001, 344, 488493.

4. Dodick, V.W.; Blumenfeld, A.; Silberstein, S.D. Botulinum neurotoxin for the treatment of migraine and other primary headache disorders. Clin. Dermatol. 2004, 22, 76-81. 